\title{
Cemitério dos vivos: análise sociológica de uma prisão de mulheres
}

LEMGRUBER, Julita. 2. ${ }^{\mathrm{a}}$ ed., Rio de Janeiro: Forense, 1999.

LUIZ ANTÔNIO BOGO CHIES

Resultado de uma intensa pesquisa teórica e de campo - esta desenvolvida entre os anos de 1976 e 1978 no Instituto Penal Talavera Bruce, Rio de Janeiro -, que compôs o Mestrado em Sociologia de Julita Lemgruber junto ao IUPERJ (Instituto Universitário de Pesquisas do Rio de Janeiro), a obra "Cemitério dos vivos: análise sociológica de uma prisão de mulheres", continua hoje tão atual quanto na época de sua 1ae edição (1983, editora Achiamé).

Neste sentido, sua própria autora comenta, no prefácio à 2ª edição, que as mudanças ocorridas na instituição entre os anos de 1976 e 1997 foram todas conjunturais; em sua estrutura, em essência, a instituição permanece a mesma... ao que podemos agregar que os antagonismos, paradoxos e as perversidades das práticas e dinâmicas sociais e jurídico-penitenciárias igualmente pouco se alteraram (talvez se tenham somente sofisticado, haja vista a recente aprovação da lei n.. 10.792/03, que altera dispositivos da Lei de Execução Penal, e institui o Regime Disciplinar Diferenciado).

Também o que pouco mudou nesse período foi o caráter esquálido da bibliografia existente sobre o sistema penitenciário no Brasil, como registra o comentário de Dorrit Harazim (presente na contracapa desta 2aㅡ edição), ao que complementa, com igual perspicácia, que "o livro de Julita Lemgruber continua abrindo portas, arrancando o tema de sua clandestinidade", sendo, pois, "mais atual do que nunca".

\footnotetext{
* Professor Ajunto da Universidade Católica de Pelotas (UCPel), responsável pela disciplina de Sociologia Jurídica. Doutor em Ciências Jurídicas e Sociais, pela Universidad del Museo Social Argentino (UMSA - Buenos Aires, Argentina). Doutorando em Sociologia pela Universidade Federal do Rio Grande do Sul (UFRGS).
} 
A obra é um criterioso e meticuloso trabalho de análise sociológica e antropológica que enfoca não só uma das mais segregadas e segregadoras instituições modernas - a prisão, esta peça basilar da maquinaria do castigo e da punição nas sociedades ocidentais, industriais e capitalistas - mas, também, de forma sem igual em nossa realidade acadêmico-científica, a mulher presa: duplamente estigmatizada como transgressora (da ordem social e de seu papel materno e familiar) numa sociedade que é fruto de ideologia machista e patriarcal.

Esta 2a edição, sobretudo à vista das significativas alterações no quadro da conflitividade social brasileira, no quadro da própria instituição que serviu de campo para a pesquisa, bem como nos quadros gerais da legislação e das instituições da execução penal, apresenta alguns aspectos revistos e atualizados. Tais, entretanto, e mesmo que alguns, em especial os legais, merecessem uma maior acuidade, não desnaturam a estrutura e a contributividade da obra em sua originalidade, pelo contrário, reforçam-na para o momento recente.

Assim, a relação entre "A Mulher e o Crime" é o ponto introdutório da obra, no qual Lemgruber apresenta e discute orientações teóricas que buscam explicar tanto a etiologia da mulher criminosa como a diferença nas taxas de criminalidade entre homens e mulheres. Perpassando as perspectivas biológicas e avançando sobre as explicações socioestruturais, além das teorias de socialização e de papéis, a autora conduz-nos à conclusão de que "à medida que as disparidades sócio-econômicas entre sexos diminuem, há um aumento recíproco da criminalidade feminina" (1999, p. 6); do que se tem, então, e haja vista a precarização crescente das condições sociais de sobrevivência para a população em geral, independentemente de gêneros e papéis, uma tendência ao agravamento não só da questão penitenciária, mas igualmente da "mulher presa".

O tópico seguinte da obra (Capítulo I) - "Notas sobre o Trabalho de Campo" - constitui-se em obrigatória leitura para pesquisadores do sistema penitenciário e de suas instituições e grupos. Neste, a metodologia da pesquisa 
- referenciais e técnicas - é exposta em conjunto com um depoimento reflexivo das peculiaridades do campo nas dinâmicas de investigação; um campo que é permeado por inseguranças e desconfianças, ocultações e busca de privilégios.

O Instituto Penal Talavera Bruce nos é apresentado no Capítulo II, quando as dimensões físico-espaciais de distribuição da privação da liberdade são descritas, bem como a disponibilidade e a precariedade de seus serviços de assistência (médicos, dentários, sociais, educacionais, jurídicos); nessa descrição merecem destaques o fato de a instituição, à época (19761978), possuir, além de um pavilhão destinado às presas políticas, uma creche (que recebia filhos de apenadas, estes até os sete anos de idade) e uma cantina (em sistema privado de exploração).

A rotina das apenadas, seu dia-a-dia, também é objeto desse capítulo, no qual são igualmente analisados os ritos de ingresso na instituição e os dias de visita. Percebe-se, já a partir destas análises, uma perspectiva de maior vigilância sobre as apenadas - o que será ponto de outras reflexões na obra - e que é marca do reforço às concepções e aos efeitos infantilizantes das práticas punitivas das instituições totais, numa maximização do preconceito da fragilidade e debilidade femininas.

Ainda no contexto desse capítulo, é apresentado o perfil da população reclusa na instituição. Não obstante a crítica de Lemgruber às estatísticas acerca das taxas de criminalidade que envolvem as "cifras negras e cinzentas", ${ }^{1}$ a análise da população, à época institucionalizada no Talavera Bruce, confirma a opção prioritária da seletividade do sistema punitivo nas camadas e categorias sociais mais desfavorecidas, reforçando, pois, as noções de vulnerabilidade de segmentos específicos da sociedade.

O terceiro capítulo é dedicado à análise da Administração e do Corpo de Guardas. Neste sentido, os destaques estão na possibilidade de análise

1 Tais cifras envolvem casos que não chegam ao conhecimento do sistema punitivo e, também, aqueles que neste se perdem por disfunções do mesmo. 
comparativa, através dos relatos da pesquisa de campo, de dois modelos de administração experienciados na instituição. O primeiro, anterior a março de 1976, segundo a autora, pode ser caracterizado como "um sistema em que o poder era baseado na força: o controle era exercido a partir da coerção física. Infrações ao Regulamento eram reprimidas com violência e casos de espancamento de internas por guardas e chefes eram comuns" (1999, p. 67); já o segundo modelo, vigente à época da pesquisa (1976-1978), é marcado pela ambigüidade pois, conforme Lemgruber, se, por um lado, procurou dedicar um tratamento mais humano às internas, por outro implantou uma filosofia nitidamente paternalista e exageradamente moralista; "A repressão baseada na coerção física violenta foi substituída por um tipo de repressão marcadamente psicológica, apoiada nos mais diferentes tipos de ameaças, principalmente na perda de determinados privilégios" (1999, p. 71).

A análise comparativa de tais modelos administrativos, como procedida por Lemgruber, leva-nos a identificar surpreendentes câmbios nos vínculos de solidariedade entre as reclusas. Ao comentar a transformação, a autora registra que o estilo de administração anterior a março de 1976, embasado em coerções violentas, impõe sofrimento mas pode exercer grande influência na organização interna da massa carcerária, estabelecendo uma modalidade específica, não obstante violenta, de vínculos de solidariedade e coesão, ao passo que a passagem para um estilo burocrático e meritório (mas paternalista e moralista) de concessão e busca de privilégios, é capaz de provocar rupturas na coesão das internas, estimuladas, inclusive, à prática da delação. Diante de tal conclusão, convém, contudo, ressaltar a opinião de Lemgruber: "Com isto, obviamente, não se quer dizer que a administração voltada para a coerção física violenta seja recomendável, apenas conta-se o que surge a partir dos depoimentos registrados" (1999, p. 71). Em nosso entendimento, registra-se mais um paradoxo penitenciário! Já no que se refere ao Corpo de Guardas, as análises da autora nos remetem aos problemas permanentes de tal categoria "funcional". A falta de preparo adequado para o exercício da atividade, o conflito no qual as(os) 
guardas são lançados diante da impossibilidade de atendimento adequado do binômio punir/ressocializar - que os compele, até mesmo por razões da estrutura e organização burocrática das instituições, a privilegiar as funções punitivas e de vigilância -, bem como os próprios efeitos prisionalizantes da instituição sobre essa categoria, são temas recorrentes na bibliografia da sociologia penitenciária e que não deixam de ser observados na realidade do campo institucional estudado por Lemgruber.

A partir do capítulo IV a atenção prioritária é ao grupo de apenadas. O primeiro enfoque recai sobre os aspectos relativos às privações e adaptações no ambiente prisional.

No que tange às privações, e com significativo suporte na obra de Gresham M. Sykes, ${ }^{2}$ Lemgruber as identifica em diversas ordens, para além da inerente privação de liberdade física (de ir e vir) que constitui a modalidade punitiva. Assim, destacam-se as privações do convívio familiar, acentuada, no caso das mulheres, pelo abandono que, em maior grau, sofrem, sobretudo, por parte de maridos e companheiros; esse abandono também se refletirá na privação do livre exercício da sexualidade que, por sua vez, também provocará efeitos nas práticas sexuais verificadas, em especial no homossexualismo carcerário. As privações são registradas também no que tange aos bens e serviços materiais (tais são amenizadas ou agravadas pela própria situação familiar da apenada, seja no sentido de esta receber auxílio familiar ou, ainda, ser exigida na manutenção do auxílio de sua família). As privações de autonomia individual, em face do tratamento infantilizador que recebem dos grupos administrativos, e de segurança, são também analisadas pela autora.

As estratégias de adaptação ao ambiente e às privações carcerárias, tais como o afastamento psicológico, a rebelião, a colonização, a prisionalização e o próprio envolvimento homossexual são descritos para, 
em seqüência, serem verificados os papéis identificáveis dentro da organização social pesquisada na instituição. Veremos, então, descritas a alcagüete (ou delatora), a cadeeira, a política, a bacana, a madrinha (ou tia), a maluca, a cobertura, a negociante, a subversiva e a guria, a fachona e a meeira (estas três últimas vinculadas às práticas homossexuais). Nem todos os papéis são excludentes entre si, mas compõem uma gama de comportamentos e práticas que constroem parte das dinâmicas internas da sociedade carcerária.

O homossexualismo é o tópico abordado no capítulo V. A análise leva em consideração tanto a repressão moralista, a prática, como os critérios de uma sociedade machista, os quais imputam a obrigatoriedade do recato à mulher, bem como sua fragilidade, da qual decorre a necessidade de maior tutela; assim, como registra Lemgruber, "não causa surpresa verificar-se que o homossexualismo é reprimido mais intensamente em prisões femininas" (1999, p. 121), sendo, inclusive, motivo de preconceitos e repulsas internas por parte das apenadas, bem como de delações na busca de privilégios e punições.

A etiologia das práticas homossexuais, que, nos ambientes carcerários, também envolve a busca de afeto em face de tantas violências e privações, é ponto a ser destacado na análise, uma vez que amplia o espectro de elementos a serem inseridos no enfoque da questão. O capítulo finaliza com uma mais detalhada descrição e análise dos papéis sociais envolvidos na relação homossexual, ou seja, as já mencionadas "guria, fachona e meeira".

Por fim, em seu último capítulo, a obra de Lemgruber aborda o trabaIho prisional. Este - elemento chave das concepções (pseudo-)legitimantes da pena privativa de liberdade em seus fins ressocialidores, haja vista a dimensão ética que o trabalho assume na sociedade moderna - é desvelado nas contradições da realidade prisional com a pragmática utilitária de sua inserção nos ambientes carcerários. No Talavera Bruce o trabalho, sob o prisma das apenadas, assim como também verificado em estudos posteriores em outros contextos prisionais (BRANT, 1994; GOIFMAN, 1998; HASSEN, 
1999) é elemento valorado por atenuar o peso do tempo - ajuda a "matar o tempo"3 - e não por sua propalada dimensão ético-social; igualmente o trabalho prisional não contribui para uma mudança substancial nas condições materiais da encarcerada, perdendo, assim, inclusive sua perspectiva relacional de "esforço-mérito-sustento-qualidade de vida".

As conclusões da obra, que sintetizando o fracasso histórico e atual da prisão se fazem acompanhar de considerações sugestivas - não no intuito de uma "ilusão reformista", sustentada no "mito do bom presídio", mas sim num compromisso crítico - para que se minorem "os efeitos perniciosos do confinamento", conduzem-nos ao reconhecimento de que a prisão:

... funciona no sentido de aviltar e estigmatizar para sempre os que por ela passam e, na medida em que não se visualiza sua extinção num futuro próximo, há que se lutar para que sua influência se torne menos perniciosa. E, por fim, se alternativas à prisão existem, urge aumentar sua abrangência e exigir sua aplicação (LEMGRUBER, 1999, p. 162).

A obra de Lemgruber, pioneira em vários sentidos, permanentemente atual no contexto da questão penitenciária, possui em seu valor, ainda e de forma exemplar, o agregar de toda uma trajetória de vida profissional da autora, que se pauta na busca comprometida e confiante de que o sofrimento humano possa ser minorado e a pena privativa de liberdade ser abolida.

3 Cumpre destacar que a pesquisa de campo é realizada em período anterior à edição da Lei de Execução Penal (Lei n. 7.210, de 1984), logo, antes que o instituto da remição fosse positivado em nosso ordenamento jurídico, viabilizando, pois, o abatimento de um dia de pena a cada três de trabalho. 


\section{Referências}

BRANT, Vinícius Caldeira. O trabalho encarcerado. Rio de Janeiro: Forense, 1994. GOIFMAN, Kiko. Valetes em slow motion - a morte do tempo na prisão: imagens e textos. Campinas: Unicamp, 1998.

HASSEN, Maria de Nazareth Agra. O trabalho e os dias: ensaio antropológico sobre trabalho, crime e prisão. Porto Alegre: Tomo, 1999.

LEMGRUBER, Julita. Cemitério dos vivos: análise sociológica de uma prisão de mulheres. 2. ${ }^{\mathrm{a}}$ ed., Rio de Janeiro: Forense, 1999.

SYKES, Gresham M.. The Society of Captives: a study of a maximum security prision. 11. ed., New Jersey: Princeton University Press, 1999.

Recebido: 23/08/2004

Aceite final: 04/11/2004

\section{Resumo}

Obra pioneira tanto nas abordagens das ciências sociais sobre os ambientes carcerários, como, nestes, sobre a questão da mulher presa, "Cemitério dos Vivos", de Julita Lemgruber, traz-nos importantes reflexões sobre as dinâmicas e processos sociais que se viabilizam no interior de um sistema absorvente e de privações. $\mathrm{O}$ texto, resultado de uma intensa pesquisa teórica e de campo - esta desenvolvida entre os anos de 1976 e 1978 no Instituto Penal Talavera Bruce, Rio de Janeiro , que compôs o Mestrado em Sociologia da autora junto ao IUPERJ (Instituto Universitário de Pesquisas do Rio de Janeiro), é permanentemente atual no contexto da questão penitenciária; possui em seu valor, ainda e de forma exemplar, o agregar de toda uma trajetória de vida profissional, que se pauta na busca comprometida e confiante de que o sofrimento humano possa ser minorado e a pena privativa de liberdade ser abolida.

Palavras-chave: prisões, mulheres prisioneiras, sociologia penitenciária. 


\section{The Cemetery of the living: a sociological analysis of a female prison \\ LEMGRUBER, Julita. $2^{\text {nd }}$ ed., Rio de Janeiro: Forense, 1999.}

\section{Luiz Antônio Bogo Chies}

A pioneer work both within social sciences approaches on prison environments and about the issue of female inmates in those environments, Julita Lemgruber's "Cemitério dos Vivos" (The Cemetery of the Living) brings us important reflections about social dynamics and processes that took place between 1976 and 1978 at Rio de Janeiro's Talavera Bruce Penitentiary. Having been the author's Sociology Master's Thesis at IUPERJ (Instituto Universitário de Pesquisas do Rio de Janeiro), the work is always up-to-date in the context of the penitentiary issue. Its value - still and exemplarily - aggregates a whole professional trajectory based on the committed and confident search for mitigating human suffering and abolishing the punishment of deprivation of freedom.

Key words: Prisons, Female inmates, Penitentiary sociology. 